\title{
Effects of Inulin-Type Fructans on Appetite, Energy Intake, and Body Weight in Children and Adults: Systematic Review of Randomized Controlled Trials
}

\author{
Anna Liber Hania Szajewska \\ Department of Paediatrics, Medical University of Warsaw, Warsaw, Poland
}

\author{
Key Words \\ Inulin-type fructans · Obesity · Overweight $\cdot$ Weight \\ management
}

\begin{abstract}
Aim: To systematically evaluate the effects of inulin-type fructan (ITF) supplementation on appetite, energy intake, and body weight (BW) in children and adults. Methods: The MEDLINE, EMBASE, and Cochrane Library databases were searched up to December 2012 for randomized controlled trials (RCTs) that compared the effects of supplementation with well-defined ITF with placebo or no intervention. Results: For the pediatric population, 4 RCTs $(n=232)$ met the inclusion criteria. In infants, very limited evidence (1 $R C T, n=62$ ) showed no effect of ITF supplementation on energy intake and BW. One RCT involving 97 nonobese adolescents aged 9 to 13 years found a reduced increase in BW in the oligofructose + inulin ( $8 \mathrm{~g} /$ day) group compared with the control group after 1 year. For the adult population, 15 RCTs $(n=545)$ met the inclusion criteria. Five RCTs found no effect of ITF supplementation on appetite sensations. Eleven RCTs found no effect of ITF supplementation on daily energy intake or energy intake during a meal tolerance test. Among 3 RCTs that assessed the effect of ITF supplementation on BW, 2 RCTs showed a (significant) reduction in BW. Of 3 RCTs that evaluated body mass index (BMI), 1 RCT showed a significant reduction in BMI in subjects supple-
\end{abstract}

mented with ITF. Conclusion: Limited data suggest that long-term administration of ITF may contribute to weight reduction.

(c) 2013 S. Karger AG, Basel

\section{Introduction}

Overweight and obesity are growing health problems, particularly in westernized societies, leading to investigations of effective preventive treatment methods. Reduction in energy intake caused by an increase in the satiety sensation is one of the potential interventions for body weight (BW) management [1].

Inulin-type fructans (ITFs) are nondigestible, fully soluble, and fermentable food ingredients with known prebiotic properties, which are found naturally in chicory, wheat, onion, or garlic. They are linear fructose polymers with $\beta(2 \rightarrow 1)$ linkages. The generic terms for ITF that are used most frequently in the scientific literature, although inconsistently, are 'inulin', 'oligofructose' and 'fructooligosaccharides' (FOS) [2]. ITF were originally proposed as functional food ingredients capable of improving parameters of the metabolic syndrome, i.e. blood glucose concentration and lipid metabolism [3,4]. More recently, it has been hypothesized that ITF may have an impact on BW. While the exact mechanism by which ITF acts remains unclear, experimental studies have shown that ITFs 
modulate the secretion of gastrointestinal hormones, thus promoting satiety (i.e. glucagon-like peptide- 1 and glucagon-like peptide-2) and decrease the level of ghrelin, which stimulates food intake, thus, leading to lower weight gain $[5,6]$. Furthermore, with their prebiotic properties ITF influence gut microbiota. The link between gut microbiota and obesity or the metabolic syndrome via increasing the energy harvest from food ingredients is more and more recognized [7-9], although it is currently impossible to describe obesogenic gut microbiota.

Several reviews have aimed to assess the influence of ITF on humans; however, there is still uncertainty with regard to their role in weight management. The aim of this review was to systematically evaluate and update evidence on the effects of ITF supplementation on appetite, energy intake, and BW in children and adults.

\section{Methods}

\section{Criteria for Selecting Studies for this Review}

Study selection was restricted to randomized controlled trials (RCTs), including crossover RCTs, that compared the effectiveness of well-defined ITF, i.e. inulin, oligofructose, and FOS, with placebo or no intervention. No restrictions regarding the doses of ITF and/or durations of the trials were applied. Participants had to be infants, children, or adults who were normal weight or overweight/obese, but otherwise healthy. Trials that included breastfed infants were excluded.

The primary outcomes were as follows: (1) appetite sensations assessed using subjective scales, preferably the Visual Analogue Scale (VAS) or other scales as used by the investigators; (2) energy intake assessed using food records, during free-choice buffets, or any other tool used by the investigators; (3) BW (kg) or body mass index (BMI) measured and calculated by the investigators. The secondary outcomes were adverse effects.

\section{Search Strategy for the Identification of Studies}

The first electronic search included the MEDLINE through PubMed, EMBASE, and the Cochrane Central Register of Controlled trials (CENTRAL) databases for trials published until October 2012; the search was updated in December 2012. Two registries for clinical trials (www.clinicaltrials.gov, www.clinicaltrialsregister.eu) were screened to identify published and ongoing studies. The references for identified studies were checked. There was no restriction on the language imposed.

A combination of two groups of key words (free text and MESH terms) related to the type of intervention and outcome was used in the search strategy:

- inulin-type fructan* OR fructans OR inulin OR inulin-enriched OR inulin* OR oligofructose OR fructooligosaccharide* OR fructo-oligosaccharide* OR prebiotic* OR prebiotic OR oligosaccharide* OR oligosaccharides

- satiety OR fullness OR hunger OR appetite OR energy intake OR food intake OR desire to eat OR prospective consumption OR Visual Analogue Scale OR dietary intake OR energy con- sumption OR meal tolerance test OR food recall OR dietary recall OR diet history OR food frequency questionnaire OR food record OR body weight OR weight OR body mass index OR BMI OR body fat mass AND body composition.

The Cochrane Highly Sensitive Search Strategies for identifying RCTs in MEDLINE was used. The EMBASE search strategy included filters to search for RCTs with human participation. While searching CENTRAL, no filters were used.

\section{Selection of Studies}

Initially, the title, abstract, and key words of every record identified with the search strategy were screened. Obviously irrelevant articles were excluded by title or abstract. Full texts were obtained for all potentially relevant studies. Differences between reviewers were resolved by discussion until consensus was reached.

\section{Data Extraction and Management}

The following data were extracted from the articles: author; year of publication; baseline characteristics of participants (age, sex, BMI); type of intervention (the terminology as used by the authors of the original papers): active product dosage: comparator; duration of the intervention; outcome measures, and results. If feasible, the data were entered into Review Manager (RevMan; version 5.1; Nordic Cochrane Center, Cochrane Collaboration, Copenhagen, Denmark, 2011).

\section{Assessment of Risk of Bias in the Studies Included}

The reviewers independently, but without being blinded to the authors or journal, assessed the risk of bias in the studies that met the inclusion criteria. The tool of the Cochrane Collaboration for assessing risk of bias was used, which includes the following criteria: adequacy of sequence generation, allocation concealment, blinding of participants, personnel, and outcome assessors and extent of loss to follow-up (incomplete outcome data). In all cases, an answer of 'yes' indicates a low risk of bias and an answer of 'no' a high risk of bias [10].

\section{Data Synthesis}

If appropriate, the data were analyzed using RevMan. The mean difference (MD), with $95 \%$ confidence interval (CI) between the experimental and control groups was selected to represent the difference in continuous outcomes. If data were presented as means \pm SE, missing standard deviations were obtained by multiplying standard errors of means by the square root of the sample size: $\mathrm{SD}=\mathrm{SE} \times \sqrt{ } \mathrm{N}$ (where $\mathrm{N}$ is the number of participants in the trial) [11]. Energy intake (in kJ) was calculated for kcal according to the formula $1 \mathrm{kcal}=4.184 \mathrm{~kJ}$. If means only (without the standard deviation of the outcomes) or no data were given, we report the results in a narrative format.

\section{Subgroup Analysis}

The following a priori separate types of analyses based on factors that could potentially influence the magnitude of the treatment response were planned: (1) administration of ITF to children or adults and (2) administration of ITF to normal weight or overweight/obese subjects. As the authors of the trials in adults often included a mixed population, the latter was not always feasible. Thus, we report data for normal weight adults, a mixed population of adults (i.e. normal and overweight adults), and overweight/ obese adults (all as defined by the authors). 
Fig. 1. Flow diagram of the identification of eligible trials.

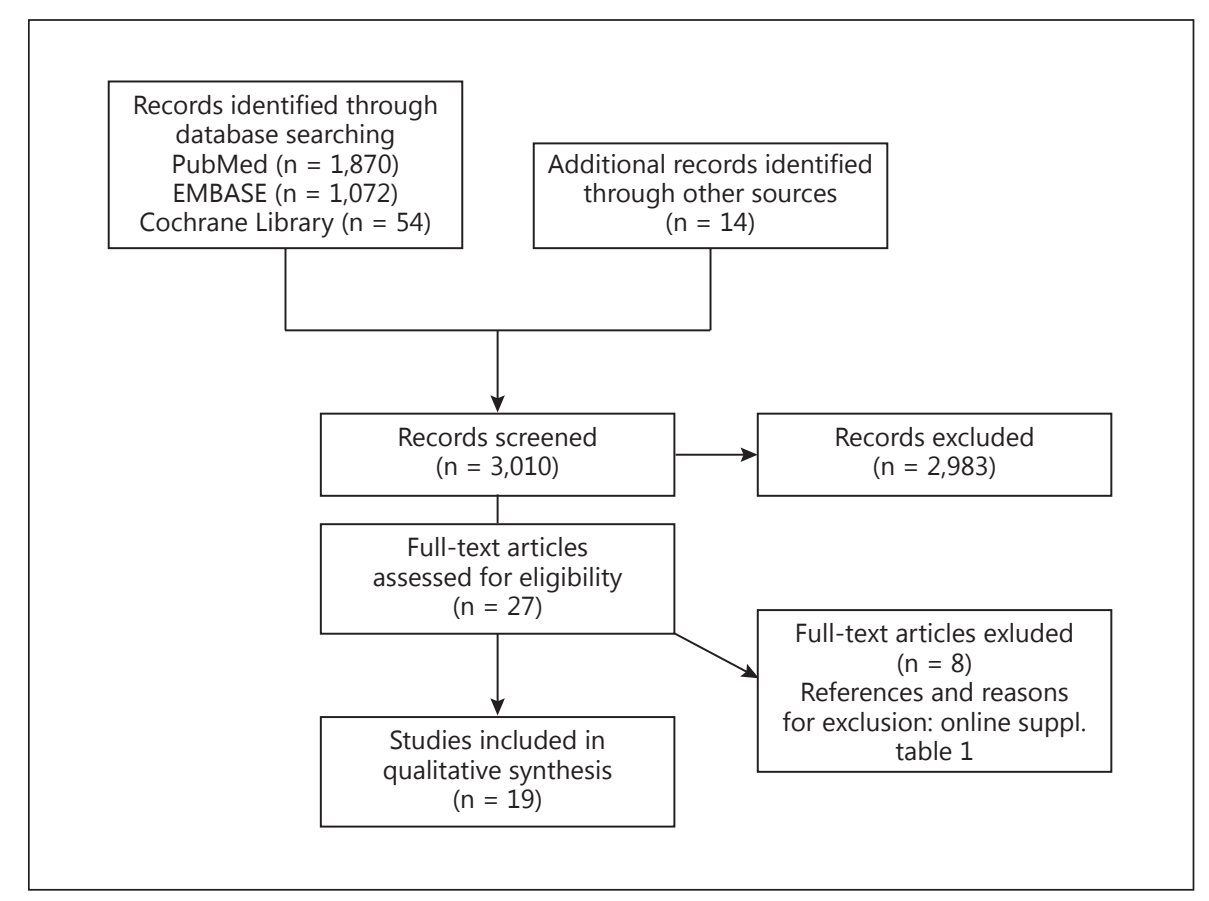

\section{Results}

\section{Trial Flow}

A total of 3,010 studies were identified from the primary electronic databases, clinical trial registries, and by checking reference lists of the trials included (fig. 1). Of these, the full texts of 27 papers were assessed. Eight potentially relevant papers were excluded from the analysis. Three ongoing studies were registered on clinicaltrials.gov. For characteristics of excluded and ongoing studies, see the online supplementary tables 1 and 2 (for all online suppl. material, see www.karger.com/doi/10.1159/000350312).

\section{Trials Included in the Study}

See table 1 for characteristics of the 19 RCTs included [12-30], of which 9 were parallel RCTs and 10 trials had a crossover design. Four RCTs involving 232 participants were carried out in children [12, 22, 24, 29], and the remaining 15 RCTs involving 545 participants were carried out in adults. The trials were heterogeneous in terms of interventions (type, dose, and duration) and outcome. In some trials, interventions other than supplementation with ITF were assessed. In particular, Karalus et al. [21] conducted a 5-arm study to assess the influence of supplementation with different types of fibers (oligofructose, inulin, wheat, and corn) and a no-fiber control. Harrold et al. [18] conducted a 4-arm, crossover RCT to assess the effects of consumption of an inulin-based soluble fermentable fiber, patented herb extract Yerbe Maté, Guarana and Damiana (YGD) and both combined compared with a control product. The study by Tovar et al. [28] was a 4-arm RCT that assessed the effects of inulin, partial meal replacement, both combined and a control product. However, here we only report data that fulfilled the inclusion criteria for this systematic review. Among 4 RCTs that involved overweight and obese subjects only, the participants followed a low-caloric diet in 2 RCTs (Genta et al. [16] and Tovar et al. [28]). In the study by Genta et al. [16], the low-caloric diet consisted of carbohydrates, fat, protein $(50,30$ and $15 \%$ of total energy intake, respectively) and $10 \mathrm{~g}$ of dietary fiber/day, as well as the exclusion of food products containing large amounts of FOS. In the study by Tovar et al. [28], the low-caloric diet consisted of educating subjects with a printed guideline developed according to the official food guide for the Mexican population and the National Institutes of Health guide to treat overweight and obese adults. In 2 RCTs (Dewulf et al. [15] and Parnell and Reimer [25]) diet was not regulated.

\section{Risk of Bias in the Studies Included}

Table 2 shows the results of the assessment of risk of bias of the trials included. All of them had some methodological limitations, with unclear allocation concealment applying to 17 trials. One of the studies had a single-blind
Liber/Szajewska 


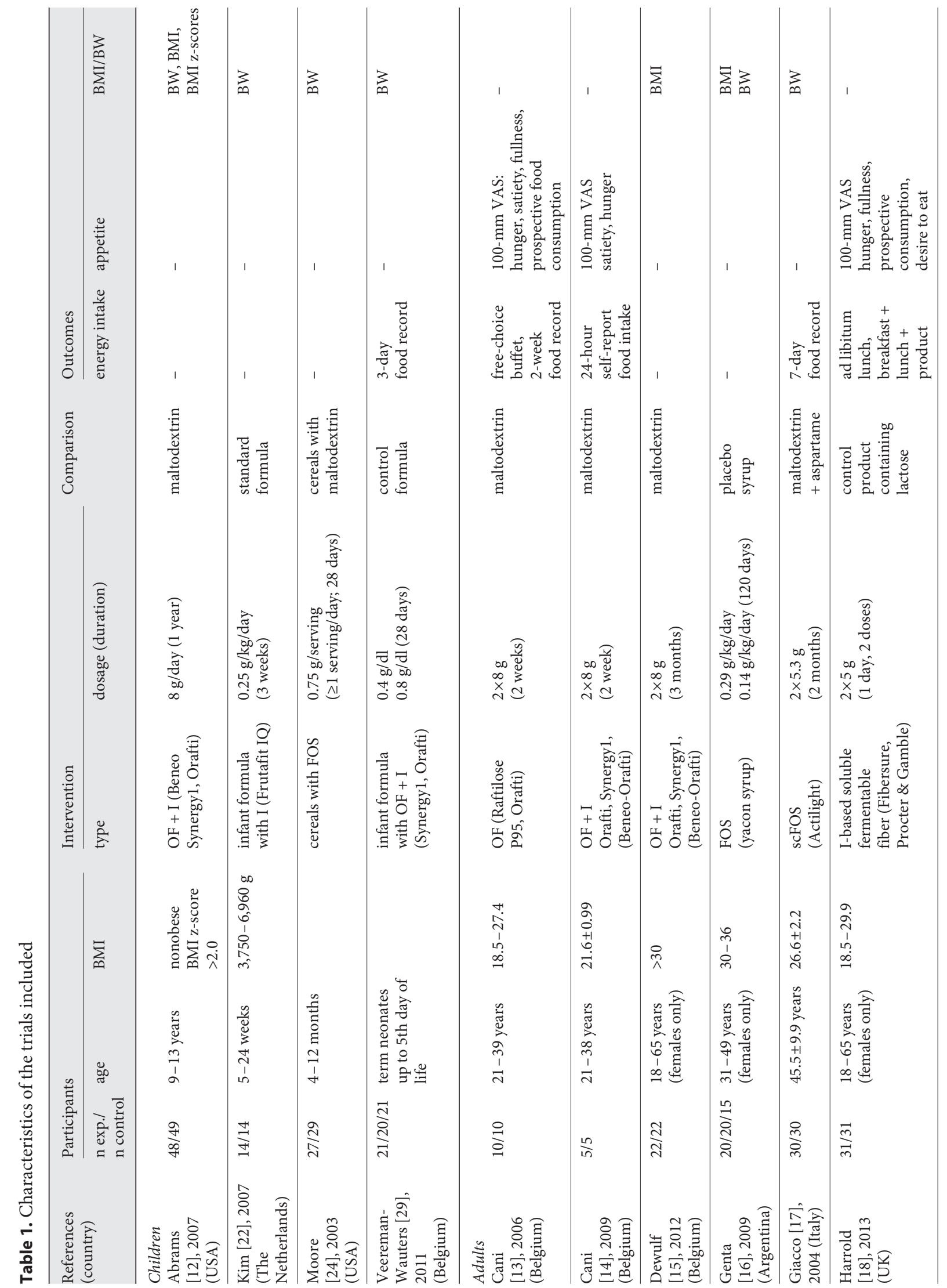




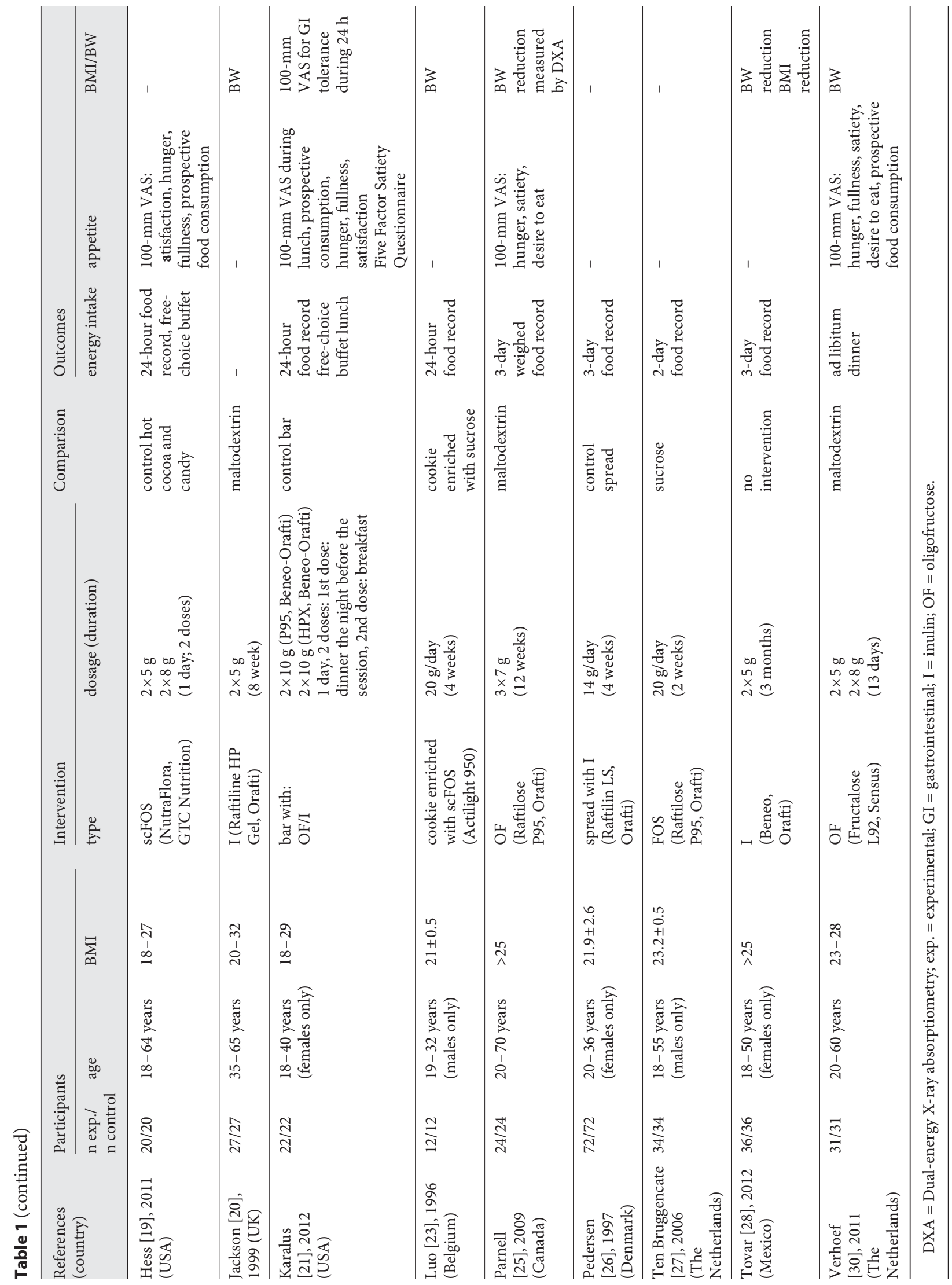


Table 2. Methodological assessment of the trials included

\begin{tabular}{|c|c|c|c|c|c|c|}
\hline \multicolumn{7}{|l|}{ Children } \\
\hline Abrams [12], 2007 & parallel & unclear & yes & unclear & 97 & PP \\
\hline Kim [22], 2007 & crossover, no washout period & unclear & unclear & unclear & 100 & ITT \\
\hline Veereman-Wauters [29], 2011 & parallel & unclear & yes & unclear & 68 & unclear \\
\hline \multicolumn{7}{|l|}{ Adults } \\
\hline Cani [13], 2006 & crossover, 2-week washout period & unclear & single blinded & unclear & 100 & ITT \\
\hline Cani [14], 2009 & parallel & unclear & yes & unclear & 100 & ITT \\
\hline Harrold [18], 2013 & crossover, 48-hour washout period & yes & yes? & yes & 94 & $\mathrm{PP}$ \\
\hline Hess [19], 2011 & crossover, at least 1 -week washout period & unclear & yes & unclear & $100^{1}$ & unclear \\
\hline Jackson [20], 1999 & parallel & unclear & yes & unclear & 100 & ITT \\
\hline Karalus [21], 2012 & crossover, washout period at least 1 week & yes & unclear & unclear & 100 & ITT \\
\hline Luo [23], 1996 & crossover, 2-week washout period & unclear & yes & unclear & 100 & ITT \\
\hline Parnell [25], 2009 & parallel & yes & yes & unclear & 81 & unclear \\
\hline Pedersen [26], 1997 & crossover, no washout period & unclear & yes & unclear & 89 & unclear \\
\hline Ten Bruggencate [27], 2006 & crossover, 2-week washout period & unclear & yes & unclear & 100 & ITT \\
\hline Tovar [28], 2012 & parallel & yes & no & unclear & 82 & $\mathrm{PP}$ \\
\hline
\end{tabular}

ITT = Intention-to-treat analysis; PP = per protocol analysis. ${ }^{1}$ One subject did not complete the study and was replaced.

design, and 1 was an open trial. In 10 RCTs, the data were analyzed using the intention-to-treat principle, whereas 4 trials were analyzed per protocol. In 5 trials, the method of analysis was unclear. Three RCTs $[17,22,26]$ of the 10 crossover studies lacked a washout period.

\section{Effects of Interventions}

Appetite

Children. No RCT evaluated the effect of ITF on appetite.

Normal Weight Adults. In only 1 small RCT $(\mathrm{n}=10)$, in 2009, Cani et al. [14] assessed satiety and hunger in normal weight adults. The investigators found no significant differences in hunger and satiety ratings between the experimental group (oligofructose plus inulin, $16 \mathrm{~g} /$ day) and the control group ( $\mathrm{p}=0.149$ and $\mathrm{p}=0.151$, respectively) with the use of a $100-\mathrm{mm}$ VAS after a test meal (free-choice buffet breakfast) that was performed at the end of the 2-week supplementation period. Compared with baseline, the consumption of the experimental product significantly lowered hunger assessed $180 \mathrm{~min}$ after the meal $(\mathrm{p}=0.024)$; this variable remained unchanged in the placebo group $(\mathrm{p}=0.15)$.

Mixed Population (Normal Weight and Overweight Adults). The effect of ITF (oligofructose, inulin, and short-chain-FOS, scFOS) on appetite sensations was evaluated in 5 crossover trials (Cani et al. [13], Harrold et al. [18]), Hess et al. [19], Karalus et al. [21], and Verhoef et al. [30]) involving 114 participants. The daily doses of ITF ranged from 10 to $20 \mathrm{~g}$, and the durations of the interventions ranged from 1 day to 2 weeks.

Two RCTs (Hess et al. [19] and Karalus et al. [21]) that provided a measure of variance did not show an effect of supplementation with ITF on satiety, fullness, 


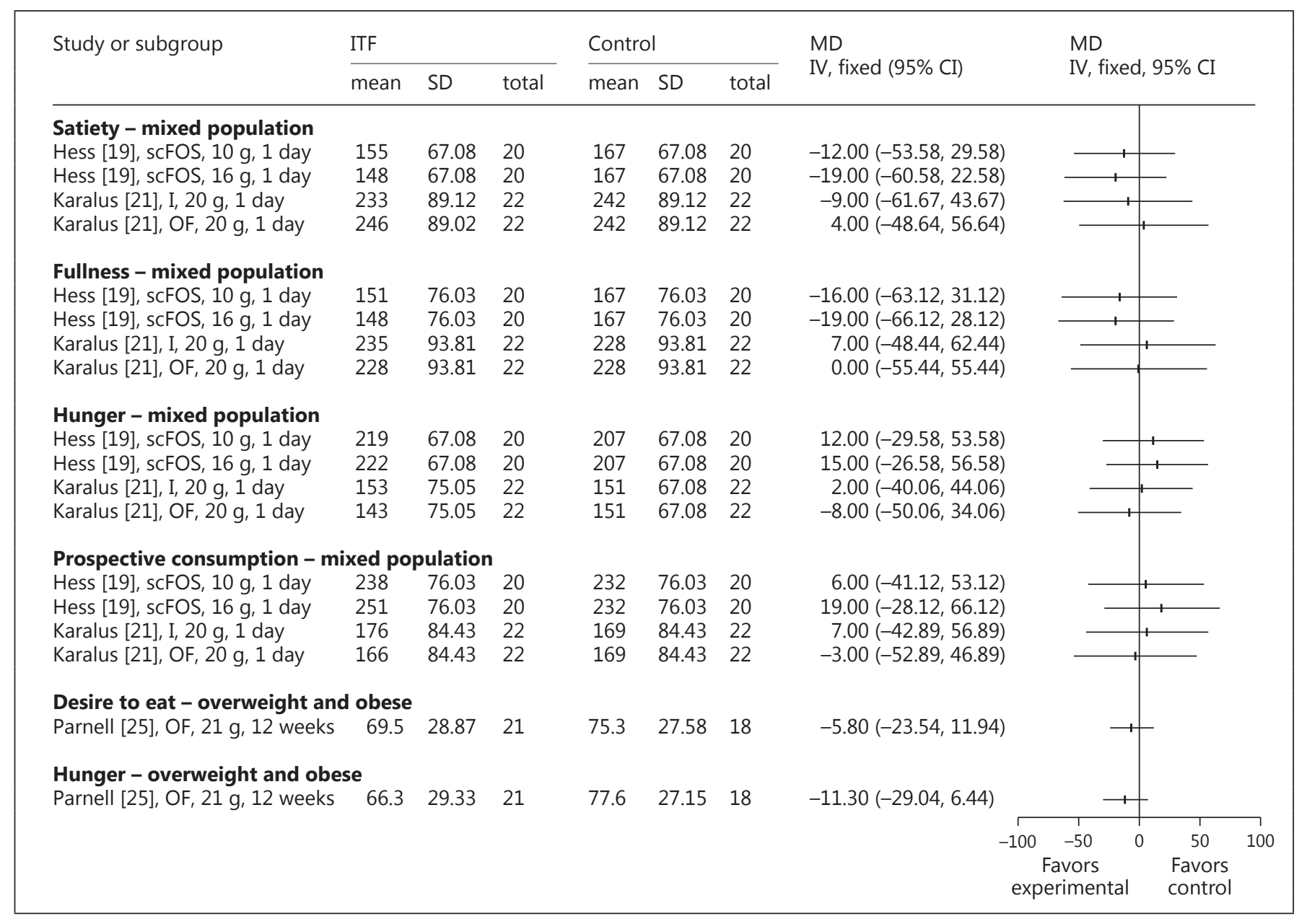

Fig. 2. Effect of ITF on satiety, fullness, and hunger in adults. $I=I n u l i n ; O F=$ oligofructose.

hunger, prospective consumption, and desire to eat (fig. 2).

Three RCTs (Cani et al. [13], Harrold et al. [18], and Verhoef et al. [30]) provided data only in figures; therefore, we report the results in a narrative format. In a small $(\mathrm{n}=10)$, randomized, single-blinded, crossover, pilot study, Cani et al. [13] evaluated appetite sensations during meal tolerance tests (breakfast, lunch, and dinner) after a 2-week experimental phase. Compared with placebo (maltodextrin), oligofructose ( $16 \mathrm{~g} /$ day) significantly increased satiety after breakfast $(\mathrm{p}=0.04)$, with no significant differences between groups in hunger $(\mathrm{p}=0.88)$, fullness $(\mathrm{p}=0.58)$, and prospective food consumption $(\mathrm{p}=0.23)$. After dinner, satiety was also increased $(\mathrm{p}=0.04)$, hunger was significantly reduced $(\mathrm{p}=0.04)$, and prospective food consumption was decreased $(\mathrm{p}=0.05)$; fullness was similar in both groups.
After lunch, no significant differences were observed between the experimental and control groups with respect to satiety $(\mathrm{p}=0.92)$, hunger $(\mathrm{p}=0.84)$, fullness $(\mathrm{p}=$ $0.98)$, and prospective food consumption $(\mathrm{p}=0.35)$. Another crossover RCT $(n=31$; Verhoef et al. [30]) found that compared with placebo (maltodextrin, $16 \mathrm{~g} /$ day), oligofructose supplementation (10 and $16 \mathrm{~g} /$ day for 13 days) had no effect on appetite sensations assessed after a test meal. The third RCT (Harrold et al. [18]) included 62 participants and found no effect of an inulin-based, soluble, fermentable fiber ( $10 \mathrm{~g} /$ day) compared to the control product on hunger, fullness, prospective consumption, and desire to eat assessed within $24 \mathrm{~h}$ after product consumption.

Overweight and Obese Adults. One RCT ( $\mathrm{n}=39$; Parnell and Reimer [25]) showed that compared to placebo (maltodextrin), oligofructose supplementation (21 g/day)
48

Ann Nutr Metab 2013;63:42-54 DOI: $10.1159 / 000350312$
Liber/Szajewska 


\begin{tabular}{|c|c|c|c|c|c|c|c|c|c|}
\hline \multirow[t]{2}{*}{ Study or subgroup } & \multicolumn{3}{|c|}{ Experimental } & \multicolumn{3}{|c|}{ Control } & \multirow{2}{*}{$\begin{array}{l}\text { MD } \\
\text { IV } \text {, fixed }(95 \% \text { CI })\end{array}$} & \multirow{2}{*}{\multicolumn{2}{|c|}{$\begin{array}{l}\text { MD } \\
\text { IV, fixed, 95\% CI }\end{array}$}} \\
\hline & mean & SD & total & mean & SD & total & & & \\
\hline \multicolumn{10}{|l|}{ kcal/day - normal weight } \\
\hline Cani [13], OF + I, $16 \mathrm{~g}, 2$ weeks & 2,339 & 487 & 5 & 2,501 & 935 & 5 & $-162.00(-1,086.05,762.05)$ & & \\
\hline Luo [23], scFOS, 20 g, 4 weeks & 2,564 & 192 & 12 & 2,620 & 214 & 12 & $-56.00(-218.67,106.67)$ & $\hookrightarrow$ & \\
\hline Pedersen [26], I, 14 g, 4 weeks & 2,151 & 459 & 64 & 2,199 & 502 & 64 & $-48.00(-214.65,118.65)$ & $\longrightarrow$ & \\
\hline \multicolumn{10}{|l|}{ kcal/day - mixed population } \\
\hline Giacco [17], scFOS, $10.6 \mathrm{~g}, 2$ months & 1,915 & 539 & 30 & 1,794 & 573 & 30 & $121.00(-160.50,402.50)$ & & \\
\hline Karalus [21], I, 20 g, 1 day & 1,697 & 666 & 22 & 1,669 & 666 & 22 & $28.00(-365.57,421.57)$ & & \\
\hline Karalus [21], OF, 20 g, 1 day & 1,714 & 666 & 22 & 1,669 & 666 & 22 & $45.00(-348.57,438.57)$ & & \\
\hline \multicolumn{10}{|l|}{ kcal/meal - mixed population } \\
\hline Harrold [18], I, 10 g, 1 day & 662 & 2,374 & 58 & 752 & 2,256 & 58 & $-90.00(-932.83,752.83)$ & & \\
\hline Hess [19], scFOS, 10 g, 1 day & 1,040 & 259 & 20 & 1,034 & 259 & 20 & $6.00(-154.53,166.53)$ & & . \\
\hline Hess [19], scFOS, 16 g, 1 day & 1,024 & 259 & 20 & 1,034 & 259 & 20 & $-10.00(-170.53,150.53)$ & & \\
\hline Verhoef [30], OF, 10 g, 13 days & 759 & 355 & 29 & 711 & 355 & 29 & $48.00(-134.72,230.72)$ & & - \\
\hline Verhoef [30] OF, $16 \mathrm{~g}, 13$ days & 669 & 387 & 29 & 711 & 355 & 29 & $-42.00(-233.14,149.14)$ & - & \\
\hline \multicolumn{10}{|l|}{ kcal/day - overweight and obese } \\
\hline \multirow[t]{3}{*}{ Tovar [28], I, $10 \mathrm{~g}, 3$ months } & 1,243 & 2,467 & 27 & 1,101 & 1,545 & 28 & $142.00(-950.43,1,234.43)$ & & \\
\hline & & & & & & & & $\begin{array}{rrr}1 & 1 \\
-1,000-500 & 0\end{array}$ & 5001,000 \\
\hline & & & & & & & & $\begin{array}{l}\text { Favors } \\
\text { experimental }\end{array}$ & $\begin{array}{l}\text { Favors } \\
\text { control }\end{array}$ \\
\hline
\end{tabular}

Fig. 3. Effect of ITF on daily energy intake and energy intake assessed during a meal tolerance test in adults. $\mathrm{I}=\mathrm{Inulin}$; OF = oligofructose.

had no effect on appetite sensations in overweight and obese subjects after a 3-month intervention period (fig. 2).

\section{Energy Intake}

Infants. One RCT conducted in 81 infants showed that compared to standard infant formula, formula supplemented with oligofructose and inulin at a dose of 0.4 or $0.8 \mathrm{~g} / \mathrm{dl}$, as well as formula supplemented with galactooligosaccharides plus FOS, had no effect on daily energy intake after a 28-day study period (data not shown; Veereman-Wauters et al. [29]).

Normal Weight Adults. The impact of ITF (oligofructose, inulin, and scFOS; dosage: $14-20 \mathrm{~g} /$ day) on energy intake was assessed in 4 RCTs involving 128 participants (Cani et al. [14], Luo et al. [23], Pedersen et al. [26], and Ten Bruggencate et al. [27]). The duration of the interventions in these studies varied from 2 to 4 weeks. Energy intake was assessed during ad libitum meals or from food records completed by the participants. None of the three trials that reported data on the effects of ITF consumption on daily energy intake or energy intake during the ad libitum meal demonstrated a significant difference between the experimental and control groups (fig. 3). Additionally, a double-blind, placebo-controlled, crossover study of $2 \times 2$ weeks with a washout period of 2 weeks conducted in 34 healthy men found no difference in daily energy intake between the experimental group (FOS, $20 \mathrm{~g} /$ day) and the placebo group (sucrose); however, the data were not presented (Ten Bruggencate et al. [27]).

Mixed Population (Normal Weight and Overweight Adults). The impact of ITF (oligofructose, inulin, and scFOS; dosage 10-20 g/day) on energy intake was assessed in 6 RCTs involving 144 participants (Cani et al. [13], Giacco et al. [17], Harrold et al. [18], Hess et al. [19], Karalus et al. [21], and Verhoef et al. [30]). The duration of the interventions in these studies varied from 1 day to 2 months, and mostly supplementation lasted 2-4 weeks. Energy intake was assessed during ad libitum meals or from food records completed by the participants. Five out of the 6 RCTs that reported data on the effect of ITF on daily energy intake or energy intake during ad libitum meals did not find a significant difference between the experimental and control groups (fig. 3).

In 2006, Cani et al. [13] assessed daily energy intake during a 2-week experimental period (fig. 3) and energy intake during the free-choice buffet (breakfast, lunch, and dinner) performed at the end of the experimental phase. The latter results were expressed as a percentage 


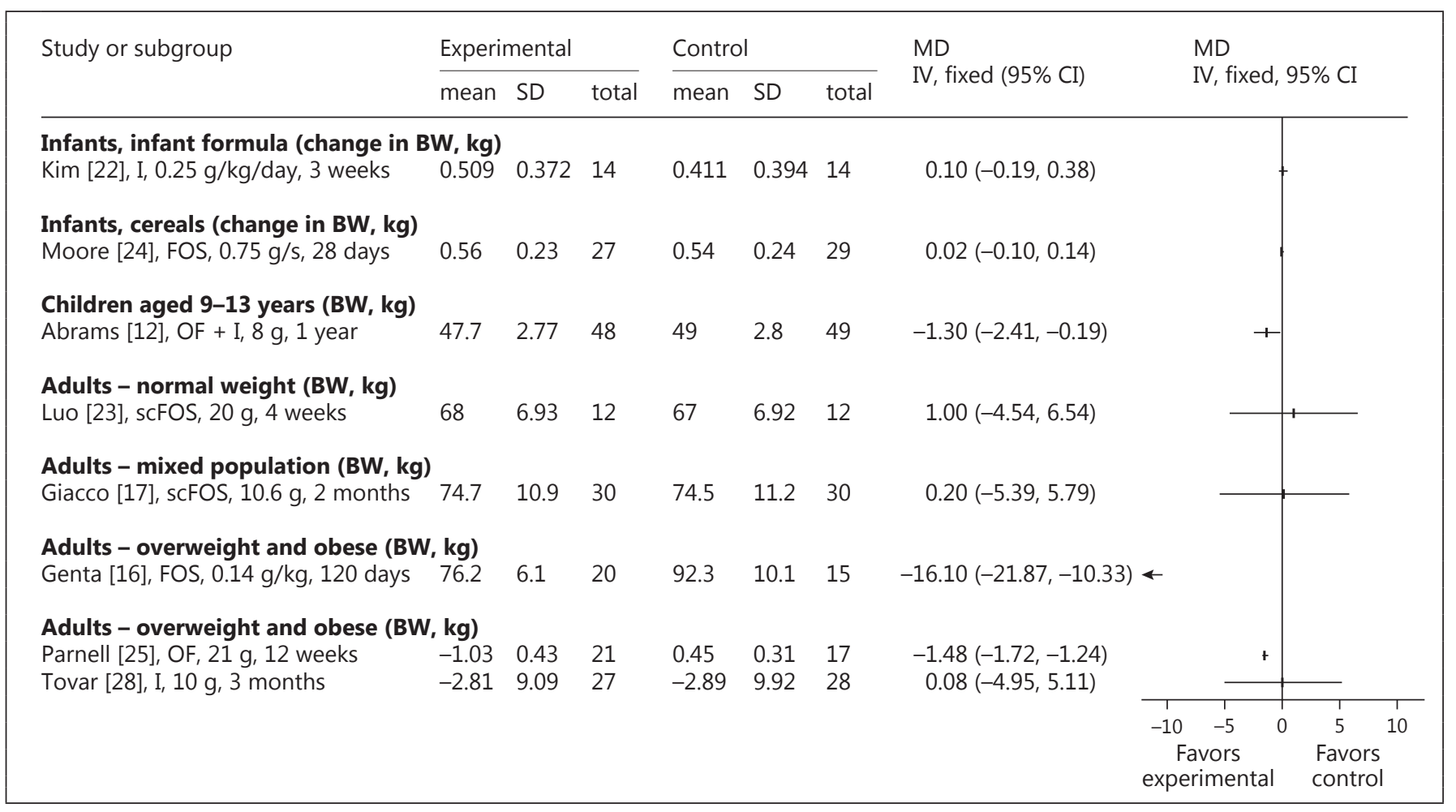

Fig. 4. Effect of ITF on BW in children and adults. $\mathrm{I}=$ Inulin; $\mathrm{OF}=$ oligofructose.

of energy intake observed in the control group. The 24hour energy intake assessed during the test day in the experimental group was lower by about $5 \%$ compared with that observed in the placebo (maltodextrin) group $(\mathrm{p}<0.05)$. Compared with placebo, oligofructose significantly reduced energy intake (by about 10\%) after breakfast $(\mathrm{p}<0.01)$ and lunch $(\mathrm{p}<0.05)$; however, no significant difference was observed after dinner between groups $(\mathrm{p}>0.05)$.

Overweight and Obese Adults. The effect of ITF on energy intake in overweight and obese subjects was assessed in 2 RCTs ( $n=120$; Parnell and Reimer [25] and Tovar et al. [28]). In the first study [25], energy intake was assessed every 3 weeks over a 12 -week study period. There was no significant difference between the experimental group (oligofructose, $21 \mathrm{~g} /$ day; $\mathrm{n}=21$ ) and the placebo group (maltodextrin, $\mathrm{n}=19$ ) with one exception. By week 6 , a $29 \%$ reduction in total energy intake was reported in the oligofructose group compared with the control group $(\mathrm{p}=0.002)$. The second RCT [28] conducted in subjects on a low-caloric diet $(\mathrm{n}=55)$ found that compared with no intervention, inulin ( $10 \mathrm{~g} /$ day) had no effect on energy intake after a 3-month study period (fig. 3).

\section{Body Weight}

Infants. Two RCTs assessed the effect of supplementation of infant formula. The first RCT (Kim et al. [22]) involving 14 infants aged 5-24 weeks found a similar BW in infants fed infant formula supplemented with inulin $(0.25 \mathrm{~g} / \mathrm{kg} /$ day $)$ compared with infants fed unsupplemented formula for 3 weeks (MD $0.1 \mathrm{~kg}, 95 \%$ CI -0.19 to 0.38 ; fig. 4). Also, a second RCT (VeeremanWauters et al. [29]) involving 62 term infants showed no effect of formula supplemented with ITF $(0.4 \mathrm{~g} / \mathrm{dl}$ oligofructose $+0.8 \mathrm{~g} / \mathrm{dl}$ inulin) after a 28 -day study period (data not shown by the authors of the original publication).

One RCT (Moore et al. [24]) involving 56 infants aged 16-46 weeks evaluated the effect of adding FOS to infant cereal. This study found no significant difference in weight gain between children fed FOS-supplemented infant cereal ( $0.75 \mathrm{~g}$ FOS per serving of cereal) or placebo for 28 days (MD $0.02 \mathrm{~kg}, 95 \% \mathrm{CI}-0.1$ to 0.14 ).

Children. One RCT (Abrams et al. [12]) involving 97 nonobese adolescents aged 9-13 years found a significant difference in the oligofructose plus inulin group ( $8 \mathrm{~g} /$ day) compared with the control (maltodextrin) group with re- 
Table 3. Summary of the effect of inulin-type fructans in overweight and obese adults on BW and BMI

\begin{tabular}{|c|c|c|c|c|c|c|}
\hline Reference & Participants, $\mathrm{n}$ & Intervention & Comparison & Diet & Outcome & Effect \\
\hline Genta [16], 2009 & 35 & $\begin{array}{l}\text { FOS } \\
0.14 \mathrm{~g} / \mathrm{kg} / \text { day (4 months) }\end{array}$ & placebo syrup & $\begin{array}{l}\text { low-calorie } \\
\text { diet }\end{array}$ & BMI & $\mathrm{MD}-4(-6.41$ to -1.59$)$ \\
\hline Parnell [25], 2009 & 48 & $\begin{array}{l}\text { oligofructose } \\
21 \mathrm{~g} / \text { day ( } 3 \text { months) }\end{array}$ & maltodextrin & $\begin{array}{l}\text { normal } \\
\text { diet }\end{array}$ & change in BW & $\mathrm{MD}-1.48(-1.72$ to -1.24$)$ \\
\hline Tovar [28], 2012 & 72 & $\begin{array}{l}\text { inulin } 10 \mathrm{~g} / \text { day } \\
\text { ( } 3 \text { months })\end{array}$ & $\begin{array}{l}\text { no } \\
\text { intervention }\end{array}$ & $\begin{array}{l}\text { low-calorie } \\
\text { diet }\end{array}$ & BMI reduction & NS (data not shown) \\
\hline
\end{tabular}

Total

189

NS = Nonsignificant.

spect to BW after 1 year $(47.7 \pm 0.4$ vs. $49.0 \pm 0.4 \mathrm{~kg}$, respectively; MD $-1.3 \mathrm{~kg}, 95 \% \mathrm{CI}-2.41$ to -0.19$)$.

Normal Weight Adults. Only 1 small RCT $(\mathrm{n}=12$; Luo et al. [23]) included normal weight male participants. This study found no significant difference in BW after a 4-week consumption of cookies enriched with scFOS (20 $\mathrm{g}$ /day) compared to cookies enriched with sucrose (MD $1.00 \mathrm{~kg}, 95 \%$ CI -4.54 to 6.54 ).

Mixed Population (Normal Weight and Overweight Adults). The impact of ITF (oligofructose, inulin, scFOS) on BW was studied in 3 RCTs (Giacco et al. [17], Jackson et al. [20], and Verhoef et al. [30]) involving 115 normal weight or overweight participants. The daily dosage of ITF varied from 10 to $16 \mathrm{~g}$. Interventions lasted from 13 days to 2 months. Only 1 RCT provided data on BW (Giacco et al. [17]). In this study, the investigators found no significant effect of 2 months of scFOS (10.6 g) supplementation compared to maltodextrin (MD $0.2 \mathrm{~kg}$, $95 \%$ CI -5.39 to 5.79 ) in participants with a BMI of 26.6 \pm 2.2 (fig. 4). Two other RCTs (Jackson et al. [20] and Verhoef et al. [30]) did not provide data; however, both reported no significant differences in BW between the oligofructose group (10 or $16 \mathrm{~g} /$ day for 13 days) [30] or inulin group (10 g/day for 8 weeks) [20] and their respective control groups.

Overweight and Obese Adults. Three RCTs involving 155 participants assessed the effect of ITF supplementation on BW in kilograms (Genta et al. [16]) or on BW reduction (Parnell and Reimer [25] and Tovar et al. [28]). The duration of these interventions varied from 3 to 4 months. The findings in these trials are summarized in table 3 and figure 4.

Effects of Inulin-Type Fructans on Appetite, Energy Intake, and BW
Body Mass Index

Children. One RCT (Abrams et al. [12]) involving 97 nonobese children aged 9 to 13 years found a significant difference between the oligofructose plus inulin group (8 g/day) compared with the control (maltodextrin) group after 1 year with respect to BMI (MD $-0.53,95 \%$ CI -0.95 to -0.11 ) and the BMI z-score (MD $-0.13,95 \%$ CI -0.25 to -0.01 ; fig. 5 ).

Overweight and Obese Adults. Three RCTs involving 151 participants assessed the effect of ITF on BMI (Dewulf et al. [15] and Genta et al. [16]) or BMI reduction (Tovar et al. [28]). For a summary of the findings, see table 3 and figure 5 .

\section{Adverse Effects}

Fifteen RCTs included assessed adverse events (table 4). The most frequently reported adverse effects in the experimental groups were flatulence, abdominal rumbling, and bloatedness. Only 1 RCT (Genta et al. [16]) reported severe adverse effects (diarrhea, severe abdominal distension, flatulence, and nausea) in the FOS group $(0.29 \mathrm{~g} / \mathrm{kg}$ of BW/day), which was the reason for exclusion (by the investigators) from the trial of one of the experimental groups.

\section{Discussion}

\section{Principal Findings}

This review was designed to systematically evaluate the effects of ITF supplementation on appetite, energy intake, and BW in children and adults. In infants, very limited evidence (1 RCT only) showed no effect of ITF 
Table 4. Adverse effects reported in the studies included

\begin{tabular}{|c|c|c|}
\hline Reference & ITF & Adverse effects \\
\hline \multicolumn{3}{|l|}{ Children } \\
\hline Kim [22], 2007 & I & no adverse effects were observed \\
\hline Moore [24], 2003 & FOS & tolerance was similar in the experimental and control groups \\
\hline Veereman-Wauters [29], 2011 & $\mathrm{OF}+\mathrm{I}$ & no serious adverse events were observed \\
\hline \multicolumn{3}{|l|}{ Adults } \\
\hline Cani [13], 2006 & $\mathrm{OF}$ & abdominal rumbling and flatulence were reported during the first 3 days of OF treatment \\
\hline Cani [14], 2009 & $\mathrm{OF}+\mathrm{I}$ & $\begin{array}{l}\text { abdominal rumbling ( } 26 \% \text { of participants) and flatulence ( } 66 \% \text { of participants) were } \\
\text { observed during the first } 3 \text { days of OF treatment }\end{array}$ \\
\hline Dewulf [15], 2012 & $\mathrm{OF}+\mathrm{I}$ & $\begin{array}{l}\text { bloating, flatulence, and abdominal pain were reported during first few days in the } \\
\text { experimental group }\end{array}$ \\
\hline Genta [16], 2009 & FOS & $\begin{array}{l}\text { FOS dosage } 0.29 \mathrm{~g} / \mathrm{kg} / \text { day: significant adverse effects (diarrhea, severe abdominal } \\
\text { distention, flatulence, nausea) were the reason for exclusion of this group from the study; } \\
\text { the FOS dosage of } 0.14 \mathrm{~g} / \mathrm{kg} / \text { day was well tolerated }\end{array}$ \\
\hline Giacco [17], 2004 & scFOS & minimal adverse effects, not significantly different between groups \\
\hline Hess [19], 2011 & scFOS & $\begin{array}{l}\text { significant trend toward increasing gastrointestinal symptoms with increasing dose } \\
\text { (10 and } 16 \mathrm{~g} \text { /day) of FOS; flatulence was the most frequently reported symptom }\end{array}$ \\
\hline Karalus [21], 2012 & $\mathrm{OF}+\mathrm{I}$ & significantly more bloating and flatulence in OF and I group compared to placebo \\
\hline Luo [23], 1996 & scFOS & no adverse effects were reported \\
\hline Parnell [25], 2009 & $\mathrm{OF}$ & $\begin{array}{l}\text { subjects in the OF group experienced side effects (flatulence) in } 45 \pm 8 \% \text { of the time of the } \\
\text { study period }\end{array}$ \\
\hline Pedersen [26], 1997 & I & significantly more adverse effects (rumbling, cramps, bloatedness, flatulence) \\
\hline Ten Bruggencate [27], 2006 & FOS & significantly more adverse effects (flatulence, bloating) \\
\hline Verhoef [30], 2011 & $\mathrm{OF}$ & significantly more adverse effects (flatulence, bloating, rumbling, cramps) \\
\hline
\end{tabular}

\begin{tabular}{|c|c|c|c|c|c|c|c|c|c|}
\hline \multirow[t]{2}{*}{ Study or subgroup } & \multicolumn{3}{|c|}{ Experimental } & \multicolumn{3}{|c|}{ Control } & \multirow{2}{*}{$\begin{array}{l}\text { MD } \\
\text { IV, fixed }(95 \% \text { CI })\end{array}$} & \multirow{2}{*}{\multicolumn{2}{|c|}{$\begin{array}{l}\text { MD } \\
\text { IV, fixed, 95\% CI }\end{array}$}} \\
\hline & mean & SD & total & mean & SD & total & & & \\
\hline $\begin{array}{l}\text { Children aged 9-13 years, BMI } \\
\text { Abrams [12], OF + I, } 8 \text { g, } 1 \text { year }\end{array}$ & 19.5 & 1.039 & 48 & 20.03 & 1.05 & 49 & $-0.53(-0.95,-0.11)$ & + & \\
\hline \multicolumn{10}{|c|}{ Children aged 9-13 years, BMI z-score } \\
\hline Abrams [12], OF $+\mathrm{I}, 8 \mathrm{~g}, 1$ year & 0.25 & 0.31 & 48 & 0.38 & 0.308 & 49 & $-0.13(-0.25,-0.01)$ & & \\
\hline \multirow[t]{2}{*}{$\begin{array}{l}\text { Adults - obese, BMI } \\
\text { Genta [16], FOS, } 14 \mathrm{~g} / \mathrm{kg}, 120 \text { days }\end{array}$} & 28 & 3 & 20 & 32 & 4 & 15 & $-4.00(-6.41,-1.59)$ & $\longrightarrow$ & \\
\hline & & & & & & & & $\begin{array}{c}-4 \quad-2 \quad 0 \\
\text { Favors } \\
\text { experimental }\end{array}$ & $\begin{array}{c}24 \\
\text { Favors } \\
\text { control }\end{array}$ \\
\hline
\end{tabular}

Fig. 5. Effect of ITF on BMI. I = Inulin; OF = oligofructose. 
supplementation on energy intake and BW. In nonobese adolescents, 1 trial found a reduced increase in BW and BMI in the ITF (oligofructose + inulin) group compared with the placebo group after 1 year of supplementation. This limited evidence suggests that long-term administration of ITF may be an effective strategy in overweight/ obesity prevention in adolescents.

In adults, the effects of ITF on acute satiety (satiety assessed within $24 \mathrm{~h}$ ) and simultaneously measured energy intake were not confirmed. The results of studies involving long-term ITF consumption are inconsistent. Only 1 small RCT reported significant differences in appetite scoring and energy intake between the experimental and control groups. All other RCTs showed no beneficial effect of ITF consumption on appetite and energy intake in normal weight and obese adults. In normal weight adults and in a mixed population (normal weight and overweight adults), no effect of ITF consumption on BW was observed. In overweight and obese adults, the findings are inconsistent and limited to a small number of participants. Of 3 RCTs that compared changes in BW after ITF supplementation, 2 trials showed a (significant) reduction in BW. In 1 of these trials, the participants (in both study groups) were on a low-caloric diet. Of 3 RCTs that evaluated BMI, 1 RCT showed a significant reduction in BMI in subjects on a low-caloric diet additionally supplemented with ITF. Many of the studies reported gastrointestinal side effects (e.g. flatulence and bloating). While data from the literature suggest that these side effects, especially gastrointestinal side effects, occur more often in subjects receiving fructans with shorter chains (FOS and oligofructose) at similar doses [2], limited data did not allow us to conclude which type of ITF is most likely to cause problems.

\section{Strengths and Limitations}

To our knowledge, this systematic review is the first to assess the effectiveness of ITF supplementation both in children and adults. We gathered more data than previous narrative reviews. The evidence so far is very limited. In addition, the strength of our conclusions may be reduced by the varied methodological quality of the trials included. Potential limitations comprised unclear or inadequate allocation concealment and unclear or no blinding in some of the trials. This can overestimate the effect and skew the results in favor of either treatment, depending on the biases of the investigators. Almost half of the trials included did not report intention-to-treat analysis. Some of the crossover studies lacked a washout period, thus increasing the risk of bias originating from the 'carry-over' effect. Study limitations also included a small sample size in many trials; moreover, sample size calculations were available for only some of the trials. In some of the studies included, the study population consisted of both normal weight and overweight subjects, adding to problems with the interpretations of the findings.

\section{How This Intervention Might Work}

The mechanism by which ITF act in the context of BW improvement is still unclear. One of the proposed mechanisms is that ITF might act through appetite regulation; however, this was not well documented in the trials. While Parnell and Reimer [25] showed a significant reduction in BW after oligofructose supplementation, appetite sensations and energy intake did not differ between the experimental and control groups. Thus, the BW reduction achieved in this study cannot be explained by increased satiety and changes in energy intake. Other possible mechanisms, such as modulation of the secretion of gastrointestinal peptides involved in appetite regulation and lipid metabolism and/or the impact of ITF consumption on gut microbiota, need further evaluation $[5,6]$.

\section{Conclusions and Future Research}

Limited data suggest that long-term administration of ITF may contribute to weight reduction in adolescents and in overweight and obese adults. The mechanisms by which ITFs influence BWare still unclear, and the next step is to find which way ITFs operate. As ITFs are not homogeneous, further studies are also warranted to determine the type of the most effective substances, dose (minimal, optimal, and dose-response effect), and minimum duration of intervention for achieving weight reduction. Our current research is focusing on an evaluation of the effect of one type of ITF in overweight and obese children.

\section{Acknowledgments}

We thank Bartłomiej Zalewski for his help in the literature search and data extraction.

\section{Disclosure Statement}

The authors declare that no financial or other conflicts of interest exists in relation to the content of the article. A.L. is the recipient of a grant from the Fundacja Nutricia (Nutricia Foundation) to carry out the study on 'Effect of the oligofructose supplementation on body weight in overweight and obese children'. 


\section{References}

$>1$ Perry B, Wang Y: Appetite regulation and weight control: the role of gut hormones. Nutr Diabetes 2012;2:e26.

$>2$ Kelly G: Inulin-type prebiotics - a review: part 1. Altern Med Rev 2008;13:315-329.

-3 Bonsu NK, Johnson CS, McLeod KM: Can dietary fructans lower serum glucose? J Diabetes 2011;3:58-66.

4 Beylot M: Effects of inulin-type fructans on lipid metabolism in man and in animal models. Br J Nutr 2005;93:S163-S168.

5 Cani PD, Neyrinck AM, Maton N, Delzenne NM: Oligofructose promotes satiety in rats fed a high-fat diet: involvement of glucagonlike peptide-1. Obes Res 2005;13:1000-1007.

-6 Cani PD, Dewever C, Delzenne NM: Inulintype fructans modulate gastrointestinal peptides involved in appetite regulation (glucagon-like peptide-1 and ghrelin) in rats. Br J Nutr 2004;92:521-526.

$>7$ Ley RE, Turnbaugh PJ, Klein S, Gordon JI: Microbial ecology: human gut microbes associated with obesity. Nature 2006;444:10221023.

-8 DiBaise JK, Zhang H, Crowell MD, Krajmalnik-Brown R, Decker GA, Rittmann BE: Gut microbiota and its possible relationship with obesity. Mayo Clin Proc 2008;83:460-469.

$>9$ Delzenne NM, Cani PD: Interaction between obesity and the gut microbiota: relevance in nutrition. Annu Rev Nutr 2011;31:15-31.

10 Higgins JPT, Altman DG (eds): Assessing risk of bias in included studies; in Higgins JPT, Green S (eds): Cochrane Handbook for Systematic Reviews of Interventions. Version 5.0.1 [updated September 2008]. Cochrane Collaboration, 2008.

11 Higgins JPT, Green S (eds): Cochrane Handbook for Systematic Reviews of Interventions. Version 5.1.0 [updated March 2011]. Cochrane Collaboration, 2011. www.cochranehandbook.org.

12 Abrams SA, Griffin IJ, Hawthorne KM, Ellis KJ: Effect of prebiotic supplementation and calcium intake on body mass index. J Pediatr 2007;151:293-298.

13 Cani PD, Joly E, Horsmans Y, Delzenne NM: Oligofructose promotes satiety in healthy human: a pilot study. Eur J Clin Nutr 2006;60: 567-572.
14 Cani PD, Lecourt E, Dewulf EM, Sohet FM, Pachikian BD, Naslain D, De Backer F, Neyrinck AM, Delzenne NM: Gut microbiota fermentation of prebiotics increases satietogenic and incretin gut peptide production with consequences for appetite sensation and glucose response after a meal. Am J Clin Nutr 2009; 90:1236-1243.

15 Dewulf EM, Cani PD, Claus SP, Fuentes S, Puylaert PG, Neyrinck AM, Bindels LB, de Vos WM, Gibson GR, Thissen JP, Delzenne NM: Insight into the prebiotic concept: lessons from an exploratory, double blind inter vention study with inulin-type fructans in obese women. Gut 2012, E-pub ahead of print.

16 Genta S, Cabrera W, Habib N, Pons J, Carillo IM, Grau A, Sánchez S: Yacon syrup: beneficial effects on obesity and insulin resistance in humans. Clin Nutr 2009;28:182-187.

17 Giacco R, Clemente G, Luongo D, Lasorella G, Fiume I, Brouns F, Bornet F, Patti L, Cipriano P, Rivellese AA, Riccardi G: Effects of short-chain fructo-oligosaccharides on glucose and lipid metabolism in mild hypercholesterolaemic individuals. Clin Nutr 2004;23: 331-340.

18 Harrold JA, Hughes GM, O’Shiel K, Quinn E, Boyland EJ, Williams NJ, Halford JC: Acute effects of a herb extract formulation and inulin fibre on appetite, energy intake and food choice. Appetite 2013;62:84-90.

19 Hess JR, Birkett AM, Thomas W, Slavin JL: Effects of short-chain fructooligosaccharides on satiety responses in healthy men and women. Appetite 2011;56:128-134.

20 Jackson KG, Taylor GR, Clohessy AM, Williams CM: The effect of the daily intake of inulin on fasting lipid, insulin and glucose concentrations in middle-aged men and women. Br J Nutr 1999;82:23-30.

-21 Karalus M, Clark M, Greaves KA, Thomas W, Vickers Z, Kuyama M, Slavin J: Fermentable fibers do not affect satiety or food intake by women who do not practice restrained eating. J Acad Nutr Diet 2012;112:1356-1362.
22 Kim SH, Lee da H, Meyer D: Supplementation of baby formula with native inulin has a prebiotic effect in formula-fed babies. Asia Pac J Clin Nutr 2007;16:172-177.

23 Luo J, Rizkalla SW, Alamowitch C, Boussairi A, Blayo A, Barry JL, Laffitte A, Guyon F, Bornet FR, Slama G: Chronic consumption of short-chain fructooligosaccharides by healthy subjects decreased basal hepatic glucose production but had no effect on insulin-stimulated glucose metabolism. Am J Clin Nutr 1996; 63:939-945.

24 Moore N, Chao C, Yang LP, Storm H, OlivaHemker M, Saavedra JM: Effects of fructooligosaccharide-supplemented infant cereal: a double-blind, randomized trial. Br J Nutr 2003;90:581-587.

25 Parnell JA, Reimer RA: Weight loss during oligofructose supplementation is associated with decreased ghrelin and increased peptide YY in overweight and obese adults. Am J Clin Nutr 2009;89:1751-1759.

26 Pedersen A, Sandström B, Van Amelsvoort JM: The effect of ingestion of inulin on blood lipids and gastrointestinal symptoms in healthy females. Br J Nutr 1997;78:215-222.

27 Ten Bruggencate SJ, Bovee-Oudenhoven IM, Lettink-Wissink ML, Katan MB, van der Meer R: Dietary fructooligosaccharides affect intestinal barrier function in healthy men. J Nutr 2006;136:70-74.

-28 Tovar AR, Caamaño MD, García-Padilla S, García OP, Duarte MA, Rosado JL: The inclusion of a partial meal replacement with or without inulin to a calorie restricted diet contributes to reach recommended intakes of micronutrients and decrease plasma triglycerides: a randomized clinical trial in obese Mexican women. Nutr J 2012;11:44.

29 Veereman-Wauters G, Staelens S, Van de Broek H, Plaskie K, Wesling F, Roger LC, McCartney AL, Assam P: Physiological and bifidogenic effects of prebiotic supplements in infant formulae. J Pediatr Gastroenterol Nutr 2011;52:763-771.

-30 Verhoef SP, Meyer D, Westerterp KR: Effects of oligofructose on appetite profile, glucagonlike peptide 1 and peptide YY3-36 concentrations and energy intake. Br J Nutr 2011;106: 1757-1762. 